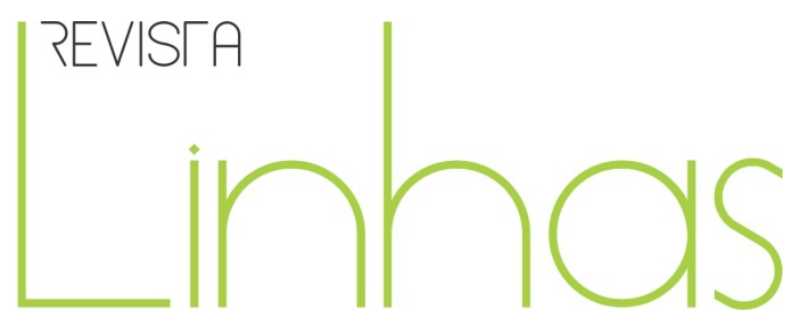

\title{
Currículo, tecnologias e inovação: para uma discussão da aprendizagem em contextos educacionais
}

\begin{abstract}
Resumo
$\mathrm{Na}$ discução contemporânea dos estudos curriculares, sobretudo entre paradigmas da modernidade e pós-modernidade (Pacheco, 2012; 2013a; Lipovetsky, 2012), o currículo está associado à inovação (Fino, 2008; 2009) e às tecnologias (Mendes, Pacheco \& Sossai, 2010), i.e., à mudança, que se pretende sucessiva e permanente, e à sociedade da informação, cada vez mais suprassumindo uma natureza reticular (Castells, 2002). Com a escrita deste artigo, procuramos explorar a relação entre currículo, inovação e tecnologias no contexto escolar, recorrendo à análise das orientações curriculares portuguesas, tendo por base alguns dos pressupostos teóricos ligados ao construcionismo (Papert, 1985). Explora-se, ainda, o significado da linguagem de aprendizagem, face à linguagem da educação (Biesta, 2013) em função das políticas de partilha de conhecimento (Steiner-Khamsi, 2012) e do modelo pós-burocrático de gestão (Maroy, 2012), que originam um novo significado para as tecnologias em contexto educacionais. Deste modo, entendemos que as tecnologias são ferramentas cognitivas (Jonassen, 2007) que tendem para novas abordagens curriculares, que implicam uma discussão não só dos métodos pedagógicos, como também das aprendizagens. Quer isto dizer, que as tecnologias, constantemente renovadas ao longo dos tempos, podem não corresponder a processos de inovação se não forem baseadas em perspetivas construcionistas, em que a matética adquire a centralidade pedagógica, de acordo com os princípios da aprendizagem construcionista de Papert (2008; 1985).
\end{abstract}

Palavras-chave: Currículo. Inovação. Tecnologias. Aprendizagem. Construcionismo.

\section{Para citar este artigo:}

PESTANA, Tânia Cristina; PACHECO, José Augusto. Currículo, tecnologias e inovação: para uma discussão da aprendizagem em contextos educacionais. Revista Linhas, Florianópolis, v. 14, n. 27, jul./dez. 2013 . p. 45 - 58

DOI: $10.5965 / 198472381427201345$

http://dx.doi.org/10.5965/198472381427201345

\section{José Augusto Pacheco}

Doutorado em Desenvolvimento

Curricular e professor da

Universidade do Minho, Instituto de Educação.

jpacheco@ie.uminho.pt 


\title{
Curriculum innovation and technology: towards an discussion of learning in educational contexts
}

\begin{abstract}
The contemporary debate about curriculum studies, mainly between paradigms of modernity and postmodernity (Pacheco, 2012; 2013a; Lipovetsky, 2010), the curriculum is linked to innovation (Fino, 2008; 2009) and technologies (Mendes, Pacheco \& Sossai, 2010), i.e., towards the changing, which intend to be successive and permanent, and to the information society, increasingly assuming a reticular nature (Castells, 2002). In this article, we explore the relationship between curriculum, innovation and technology in schools, using the analysis of the Portuguese curriculum guidelines, based on the theoretical assumptions related to Papert's constructionism (Papert, 1985). We also explore the meaning of the language learning, given the language of education (Biesta, 2013) according to the policies of sharing knowledge (Steiner-Khamsi, 2012) and the post-bureaucratic model of management (Maroy, 2012), which brings a new meaning to the technologies in educational context. Therefore, we believe that technologies are cognitive tools (Jonassen, 2007) that tend to new curricular approaches, involving not only a discussion of teaching methods, but also methods of learning. In this sense, technologies, constantly renewed over the ages, may not match the innovation process unless they are based on constructionist perspectives, in which mathetics acquires centrality teaching, according to Papert's constructionist learning principles (Papert, 2008; 1985).
\end{abstract}

Keywords: Curriculum. Innovation. Technologies.

Learning. Constructionism. 


\section{Inovação: sedução, indiferença e conformidade}

Lendo-se o Manifesto Futurista, proclamado pelo italiano Filippo Marinetti, tal como o Ultimatum Futurista às Gerações Portuguesas do Século XX, apregoado por Almada Negreiros ${ }^{1}$, inovação não faz parte do conjunto de palavras que levariam à construção do futuro. Como não cremos ser possível dizer que o tempo e o espaço morreram ontem, o presente da globalização arrasta consigo uma série de palavras tradutoras da mudança operante de outras realidades por vir, por exemplo, novas tecnologias, sociedade da informação/conhecimento e inovação. Quer dizer, assim, que a inovação, associada a conhecimento e criatividade ${ }^{2}$, é um termo ressignificado pela globalização (Pacheco, 2011), representando não só uma mudança conceitual, mas também uma alteração das práticas, encontrando no espaço da educação, em geral, e do currículo, em particular, um terreno fértil de utilização. No Thesaurus Europeu dos Sistemas Educativos (Eurydice, 2008), inovação na educação é sinónimo de inovação pedagógica, acentuando a tendência para a sua ligação à alteração das práticas, incluindo as dimensões organizacional, curricular e pedagógica ${ }^{3}$, e subordinando-se ao direito de mudar (Pacheco, 2006). Porém, a inovação por si só não representa uma intenção de mudança, nem todas as alterações se traduzem em inovação, revelando-se, nesse caso, uma adaptação.

No uso dos seus significados dicionarizados, inovar é renovar, tornar novo, inventar, adquirindo diferentes interpretações, de acordo quer com os modelos pelos quais pode ser analisada, desde os de natureza técnica aos de índole pessoal, quer com as tipologias específicas ${ }^{4}$, por exemplo, ao nível da abrangência e no modo como radicalizam a mudança. Dada a sua diversidade concetual, a inovação reveste-se de muitos significados, sendo mais fácil distinguir uma inovação tecnológica de uma inovação educacional, ainda que a pluralidade do termo seja mais expressiva quando se

\footnotetext{
${ }^{1}$ Datados, respetivamente, de 1909 e 1917.

${ }^{2}$ cf. Aprendizagem ao longo da vida ao serviço do conhecimento, da criatividade e da inovação. Projeto de relatório do Conselho e da Comissão sobre a aplicação do programa de trabalho "Educação e Formação para 2010”. http://eur-lex.europa.eu/LexUriServ/LexUriServ.do?uri=COM:2007:0703:FIN:PT:PDF [consulta em 10 de outubro de 2013].

3 Para Rui Canário, 1994, a lógica de inovação contrasta com a lógica de reforma, no mesmo sentido que é defendido por José Alberto Correia, 1989.

${ }^{4}$ Tais tipologias são descritas por José A. Pacheco, 2006, p. 151, numa síntese de vários autores.
} 
fala, por exemplo, no contexto das escolas, de inovação organizacional, de inovação curricular e de inovação pedagógica. Situando-nos epistemologicamente no campo dos estudos curriculares (Moreira, 2013; Pacheco, 2013b; 2012; Goodson, 2008; Young, 2010, Pinar, 207), utilizamos, neste artigo, o conceito de inovação para designar a mudança instituinte de outras práticas ao nível dos contextos de decisão curricular, incluindo as de natureza administrativa, ligadas à gestão e suas formas de realização, as de natureza curricular, relacionadas com o conteúdo do processo educacional, e as de natureza pedagógica, circunscritas ao espaço relacional da formação. Destacamos, assim, a inovação como um processo que institui a mudança presente nas práticas curriculares, com ênfase nas novas tecnologias (Lunardi, Mendes \& Sossai, 2013) e, consequentemente, nas práticas de aprendizagem (Papert, 2008). Com efeito, a inovação não deve ser procurada nas reformas curriculares, na medida em que ela ocorre na abertura às novas culturas em oposição às culturas escolares tradicionais (Fino, 2008), imponndo novos desafios à profissionalidade docente (Morgado, 2005; Hargreaves, 2003). Na formulação que faz sobre a teoria da mudança curricular, Goodson (2008, p. 56), assere que, numa interrelação de diferentes níveis de decisão, "a micropolítica da mudança é crucial", configuarndo-se, assim, a inovação como uma palavra que traduz, no dizer, de Morgado (2013, p. 435), “a vertigem da mudança”.

Há, no entanto, uma questão fundamental que pretendemos clarificar e que diz respeito à releitura do conceito. Baseando-nos em Lipovetsky (2013), a inovação pode ser entendida como um processo de sedução conducente à indiferença. Se a sedução "é um processo geral que tende a regular o consumo, as organizações, a informação, a educação, os costumes (ibid., p. 39), a indiferença é o resultado da banalização das coisas, por exemplo, da mudança que se pretende contínua e de forma imperativa. Poderse-á afirmar que as políticas educacionais transnacionais (Steiner-Khamsi, 2012), tal como o modelo pós-burocrático (Maroy, 2012), têm como pressuposto discursivo a inovação a todo o custo e as mudanças de origem mais técnica que pedagógica, razão porque se fala tanto, ao nível dos contextos educacionais, de competência, qualificação, eficiência, qualidade (Pacheco, 2011) e, por arrastamento, de empreendedorismo digital (Silva, Duarte \& Souza, 2013). 
O discurso sobre o novo é algo que se identifica com a palavra inovação, explorada, cada vez mais, nos espaços formais, não formais e informais de educação, como uma mudança que traduz resultados. Com efeito, a inovação agiliza-se num processo de estabilidade do que é eficaz, mesmo que tal signifique a conservação das denominadas práticas inovadoras, transformando-se elas próprias num habitus. Para Charlot (2013, p. 164), "na definição de Bourdieu, o habitus é um conjunto de disposições psíquicas (cuidado: o habitus remete a disposições psíquicas e não a normas sociais), duráveis, transponíveis, que foram socialmente estruturadas e que funcionam como princípios de estruturação de práticas e representações".

Porque a inovação é uma ilusão de mudança, é desejável, aliás tal como entende Žižek (2012), quando aborda o conceito de habitus como algo de inovador, que as práticas e as representações educacionais não estejam condicionadas pela indiferença, provocada pela linguagem da sedução. Se utilizássemos, aqui, a imagem de Lipovestky (2013, p. 67) bastante negativa, sobretudo quando se torna necessário inovar a todo o custo -, a escola seria "um corpo mumificado e os docentes um corpo fatigado, incapaz de lhe devolver a vida”. Quer isto dizer que há um excesso de discursos sobre inovação?

Poder-se-á argumentar nesse sentido se a inovação for, por um lado, o terreno discursivo das políticas de accountability (Taubman, 2009) e, por outro, o campo de práticas criativas, espontâneas e performativas, originando um certo grau de conformidade nas decisões curriculares, desde a Administração central até à sala de aula, onde a lógica de inovação se impõe como uma lógica de reforma. Assim, o uso excessivo da inovação corre "o risco de sacrificar a análise do presente à visão profética do futuro" (Charlot, 2013, p. 93), impondo às pessoas uma responsabilidade acrescida para com os resultados e transformando os contextos educacionais em espaços competitivos muito marcados pela linguagem da aprendizagem.

\section{Tecnologias e aprendizagem}

Para além da questão principal focada no ponto anterior, acrescentamos, neste ponto, uma outra: a mudança pedagógica nos contextos educacionais radicaliza as 
tecnologias como processo de inovação ao nível de uma nova linguagem da aprendizagem.

Admitir-se-ia, por conseguinte, que o termo inovação estivesse amplamente inscrito nos documentos de orientação educacional. Esta não é, porém, o que se verifica em documentos estruturantes do sistema educativo português, principalmente nos de natureza curricular e profissional. Numa busca empírica ao nível documental, verifica-se que o termo está ausente das orientações curriculares para a educação pré-escolar ${ }^{5}$, da revisão curricular dos ensinos básico ${ }^{6}$ e das metas curriculares ${ }^{7}$, aparecendo não só nas alterações para o ensino superior ligadas ao processo de Bolonha, equivalendo a inovação à mudança do paradigma de ensino de um modelo mais passivo, baseado na aquisição de conhecimentos, para um modelo baseado no desenvolvimento de competências $^{8}$, mas também nas competências organizacionais do conselho pedagógico das escolas (competindo-lhe propor o desenvolvimento de experiências de inovação pedagógica e de formação, no âmbito do agrupamento de escolas ou escola não agrupada e em articulação com instituições ou estabelecimentos do ensino superior vocacionados para a formação e a investigação ${ }^{9}$ ) e, ainda, nos deveres gerais do pessoal

5 Cf. Ministério da Educação, 2007, disponível em http://educacao.te.pt/images/downloads/documentos/orientacoes_curriculares_pre_escolar.pdf, acesso a 16 de outubro de 2013.

${ }^{6}$ Cf. Decreto-lei n. 139/2012, de 5 de julho [revisão curricular dos ensinos básico e secundário].

${ }^{7}$ Cf. Ministério da Educação, 2013, disponível em: http://www.dge.mec.pt, acesso a 14 de outubro de 2013.

${ }^{8}$ Cf. Decreto-lei n. 74/2006, de 24 de março [revisão curricular do ensino superior, Processo de Bolonha].

Uma outra governação contesta esta inovação do seguinte modo: "No preâmbulo do Decreto-lei n. ${ }^{\circ}$ 74/2006, de 24 de março, era também mencionada por diversas vezes a necessidade de "transição de um sistema de ensino baseado na ideia da transmissão de conhecimentos para um sistema baseado no desenvolvimento de competências". É, porém, errado desvalorizar o conhecimento, ou artificialmente opô-lo à noção de "competências», pelas quais ele supostamente deveria ser substituído ou nas quais deveria ser sempre englobado. Todo o sistema de ensino visa a aquisição de conhecimentos pelos estudantes, o que inclui, de forma adequada conforme os níveis, a sua apropriação, sistematização e exploração e a sua operacionalização em contextos diversos, assim como o desenvolvimento correlativo de capacidades e atitudes. O conhecimento, no entanto, é central e a Lei de Bases do Sistema Educativo é inequívoca a este respeito, sendo que nada no processo de Bolonha implica a conclusão contrária" (Preâmbulo do DecretoLei, n. 115/2013, de 7 de agosto)

${ }^{9}$ Cf. Alínea i), art. 33르. Decreto-lei n. 75/2008, de 22 de abril [gestão e administração de escolas]. 
docente (zelar pela qualidade e pelo enriquecimento dos recursos didático-pedagógicos utilizados, numa perspetiva de abertura à inovação ${ }^{10}$ ).

Ainda que não se verifique uma presença significativa do termo inovação nos documentos estruturantes do sistema educativo português, a mudança está basicamente ligada às novas tecnologias, sendo mais referenciada na educação pré-escolar do que nos ensinos básico, secundário e superior. Para a educação pré-escolar, a utilização dos meios informáticos "pode ser desencadeadora de variados sistemas de aprendizagem, permitindo a sensibilização a um outro código, o código informático, cada vez mais necessário"11.

A cultura informática, se utilizada como ferramenta cognitiva (Jonassen, 2007), torna-se num processo de inovação curricular (Fino, 2008), suprassumindo uma natureza reticular ao nível da informação e comunicação (Castells, 2002). O uso pedagógico das tecnologias nos espaços de educação e formação, por mais inovador que pareça ser, contribui para que não haja exclusividade de alguém como fonte de informação sobre o mundo, e para que a reorganização dos espaços de aprendizagem sejam completamente diferentes daqueles que suportam uma visão tradicional da aprendizagem. Estas limitações, identificadas por Charlot (2013) para o espaço escolar, obrigam a uma reflexão crítica por parte dos educadores e professores sobre o construtivismo, especialmente quando o trabalho produtivo contemporâneo é mediado pelo computador e pelos dispositivos eletrónicos, pois, à luz das correntes rotuladas como construtivistas, "a educação não consiste em transmitir conhecimentos acabados, mas em propor aos alunos situações e problemas que desencadeiem uma atividade intelectual que, com a ajuda do professor, leve ao conhecimento. Por outras palavras, a educação é o resultado de um trabalho intelectual do educando" (ibid., p. 78).

Deste modo, a aprendizagem adquire o sentido de uma atividade que significa a construção do conhecimento, não se esgotando na transmissão, uma vez que "a meta é

\footnotetext{
${ }^{10} \mathrm{Cf}$. alínea f), art. $10^{\circ}$, Decreto-lei n. $15 / 2007$, de 19 de janeiro [Estatuto da carreira docente dos educadores de infância e dos professores dos ensinos básico e secundário] Decreto Regulamentar n. 26/2012, de 21 de fevereiro [avaliação do desempenho docente].

"Cf.Ministério da Educação, 2007, disponível em:

http://educacao.te.pt/images/downloads/documentos/orientacoes_curriculares_pre_escolar.pdf, acesso a 16 de outubro de 2013.
} 
ensinar de forma a produzir a maior aprendizagem a partir do mínimo de ensino" (Papert, 2008, p.134). Considerando-se a inovação pedagógica, a escola deve promover a clarificação de ideias nos alunos através das pesquisas em grupo, uma vez que as práticas pedagógicas centradas em boas discussões e em affairs desenvolvem aprendizagens significativas e excluem a instrução e a transmissão de saberes. Consequentemente, as propostas de trabalho devem ser repletas de significado, uma vez que o aluno só será capaz de adquirir conhecimentos quando as suas regiões mentais "frias" são aquecidas pelo contacto com as suas regiões mentais "quentes". Por sua vez, o aquecimento das áreas "frias” implica um novo paradigma alicerçado na matética (Ibid.).

Em consequência, a inovação pedagógica reside na autonomia de ser, fazer e pensar, tal como preconiza ao nível da teorização crítica, aliás no seguimento de ideias perfilhadas por Adorno (2011). O desafio, para Fino (2008, p.278), passa por proporcionar aos alunos meios de aprendizagem que valorizem a construção mental e (re)construam o seu próprio conhecimento, num ambiente rico em nutrientes cognitivos, onde o aprendiz tem uma grande autonomia e "o professor inovador desempenha a função de agente metacognitivo".

Nesta perspetiva, os computadores, adaptados a diversos estilos de aprendizagem e aos diferentes níveis de capacidade e interesse, podem ser ferramentas fundamentais para criar ambientes desafiantes, novas formas de promover o diálogo intersocial, impulsionando o desenvolvimento cognitivo e permitindo maior liberdade de ação para as decisões individuais e a resolução de problemas significativos. Porém, a tecnologia, por si só, não é inovação, podendo resultar em constrangimento ou servir para fazer mais do mesmo. Esta ferramenta cognitiva só se tornará inovadora se os alunos utilizarem o computador como objeto de ampliação das suas capacidades de aprendizagem, permitindo-se-lhes pensar e elaborar projetos criativos e desafiadores, pelo que "a mudança requer uma experiência de computador muito mais contínua e social do que é possível com duas máquinas ao fundo da sala" (Papert, 2008, p.50).

Porque o construtivismo e o construcionismo têm como base a atividade do aluno, aliás já presente nas ideias de Freinet, Piaget e Vygotsky (ibid., pp. 112-113), o uso das 
novas tecnologias não tendem para acentuar o primado da linguagem da aprendizagem sobre a linguagem da educação?

O uso frequente do conceito de aprendizagem, o subsequente declínio do conceito de educação, é analisado por Biesta (2013, p. 33), reconhecendo não só que a aprendizagem se tornou "onipresente no discurso educacional contemporâneo", mas, também, que a sua afirmação se deve, entre outros fatores, "ao aparecimento das teorias construtivistas e socioculturais da aprendizagem (ibid., p. 34), ao “pós-modernismo" e à “explosão silenciosa da aprendizagem adulta” (ibid, p. 35).

Ora, e recorrendo-se, uma vez mais, às ideias de Charlot (2013, pp. 115-116), sustentando que "os próprios alunos não são construtivistas" e que "ser construtivista é trabalhar em um mundo afetivo e intelectualmente turvo", bem como às de Biesta (2013, p. 37), ao dizer que o principal problema com a nova linguagem da aprendizagem é que ela tem facilitado uma nova descrição do processo da educação em termos de uma transação económica", o uso pedagógico das tecnologias origina uma linguagem de ambivalência ao nível da aprendizagem?

Esta interrogação encontra uma resposta na análise realizada por Mendes, Pacheco e Sossai (2010, pp. 18-19): "se as tecnologias da informação e comunicação são capazes de mediar os fluxos e a virtualização que atravessa o mundo contemporâneo, potencializando "novas" linguagens no processo educativo formal, também reforçam um ethos pedagógico que, segundo Juan Carlos Tedesco (2004, p. 60), supõe “que o papel ativo do processo de aprendizagem está nos agentes externos, neste caso as tecnologias da informação e suas mensagens". Portanto, o ideal de "novas tecnologias educacionais", que perpassam políticas nacionais de educação brasileiras e portuguesas, usa e abusa da idéia de inovação curricular sob a premissa do esforço de atualização das escolas - e da cultura escolar - por meio da difusão destas próprias tecnologias, transformando-as ora em ponto de partida ora em ponto de chegada".

De facto, as tecnologias de mediação curricular, ou seja, as que são utilizadas pedagogicamente por educadores e formadores na organização de espaços de aprendizagem, desempenham diversas funções, podendo responder a várias finalidades e 
orientando o processo de aprendizagem tanto para práticas tradicionais quanto para práticas construtivistas e reconstrucionistas. Como tecnologias de inteligência (Levy, 1999), as tecnologias de informação e comunicação estão em constante inovação, incorporando a adjetivação de "novas" que sempre as caracteriza na relação do homem com a sociedade ao longo do tempo histórico. A informação e comunicação processamse, por isso, em linguagens que se completam, reconhecendo-se que a linguagem digital torna possível integrar e ampliar as linguagens oral e escrita. A questão da relação conhecimento/aprendizagem/tecnologias não pode ser dissociada de quadros políticos mais globais que configuram quer determinados tipos de sociedade, quer as estruturas de comunicação utilizadas nos processos e práticas de mediação curricular em contexto de aprendizagem (Pacheco, 2013b). Por isso, as novas tecnologias desempenham a função de controlo do conhecimento, contribuindo para a ideia da eficácia dos processos de aprendizagem e o simples uso do computador, por exemplo, não significa, por si só, uma mudança significativa no processo de aprendizagem.

Apesar de todas essas possibilidades, que a soberania das tecnologias de informação e comunicação tornam possível nas escolas, é preciso admitir a modéstia tecnológica (Postamn, 1994) na utilização dos computadores, por haver muita coisa que se pode fazer sem o recurso a computadores. A utilização dos computadores na escola é sempre reclamada pelos políticos como uma medida de futuro, sabendo-se, porém, que muito dessa pretensa mudança, quase sempre associada a uma afirmação desmesurada das potencialidades da inovação tecnológica, negligencia, como escreve Pinar (2007, p. 13), "as condições de trabalho dos professores, entre elas, o salário, o tamanho das turmas e os horários".

Por último, a ambivalência das tecnologias pode ser resgatada, e uma vez reconhecido o papel que desempenha na sociedade reticular (Castells, 2002) e na aprendizagem (Papert, 2008), através da afirmação de uma "linguagem da educação que possa servir como alternativa para a linguagem da aprendizagem” (Biesta, 2013, p. 43), aliás no sentido que é proposto por Adorno (2011, p. 27), quando argumenta que é preciso romper com a educação enquanto mera apropriação de instrumental técnico e 
receituário para a eficiência", defendendo a educação orientada para a autorreflexão, o esforço crítico a perspetiva problematizante e a emancipação.

\section{Concluindo}

Se bem que seja utilizada mais no sentido pedagógico do que nos sentidos organizacional e curricular, a inovação é uma caraterística das ditas sociedades modernas e pós-modernas, estando associada a uma pléiade de perspetivas, sendo um dos termos ressignificados pela globalização e, consequentemente, pelas políticas de partilha de conhecimento e pelo modelo pós-burocrático de gestão.

Se entendida como um processo de sedução que conduz à indiferença, a inovação tem sido apresentada como uma mudança essencialmente técnica, associada às novas tecnologias de informação e comunicação. Assim, concluímos que, nos contextos educacionais, a mudança pedagógica radicaliza as tecnologias como processo de inovação ao nível de uma nova linguagem da aprendizagem que desfavorece a linguagem da educação. Esta discussão sobre as linguagem da aprendizagem e da educação necessita de uma discussão curricular mais ampla do conhecimento e dos métodos, sem uma preocupação excessiva com as tecnologias e com a inovação pedagógica.

\section{Referências}

ADORNO, Theodor Wiesengrund. Educação e emancipação. $6^{a}$ ed.. São Paulo: Paz \& Terra, 2011.

BIESTA, Gert. Para além da aprendizagem. Educação democrática para um futuro humano. Belo Horizonte: Autêntica, 2013.

CANÁRIO, Rui, ECO: um processo estratégico de mudança. IN: R. D’ESPINEY; R.

CANÁRIO (org.), Uma escola em mudança com a comunidade Lisboa: Instituto de Inovação Educacional, p. 33-70. 1994. 
CANÁRIO, Rui. O professor e a produção de inovações. Colóquio, Educação \& Sociedade, v. 4, p. 97-121, 1993.

CASTELLS, Manuel. A era da informação: economia, sociedade e cultura. a sociedade em rede, Lisboa: Fundação Calouste Gulbenkian, V.1, 2002.

CHARLOT, Bernard. Da relação com o saber às práticas educativas. São Paulo: Cortez Editora, 2013.

CORREIA, José Alberto. Inovação pedagógica e formação de professores. Porto: Asa, 1989.

EURYDICE.Thesaurus europeu dos sistemas educativos. Lisboa: Ministério da Educação. 2008. Disponível em: <http://eurydice.giase.minedu.pt/images/stories/pdf/TESE.PT.pdf>, acesso a 13 de outubro de 2013.

FINO, Carlos. Inovação pedagógica: significado e campo (de investigação). IN MENDONÇA, Alice; BENTO, António Maria Veloso (Org.), Educação em tempo de mudança. Funchal: Grafimadeira, p. 277-287, 2008.

FINO, Carlos. Inovação e invariante (cultural). IN: RODRIGUES, Liliana;BRAZÃO, Paulo (Org.). Políticas educativas: discursos e práticas. Funchal: Grafimadeira, pp. 192-209, 2009.

GOODSON, Ivor. As políticas de currículo e de escolarização. Petrópolis: Editora Vozes, 2008.

HARGREAVES, Andy. O ensino na sociedade do conhecimento. A educação na era da insegurança. Porto: Porto Editora, 2003.

JONASSEN, David. Computadores, ferramentas cognitivas. Desenvolver o pensamento crítico nas escolas. Porto: Porto Editora, 2007.

LÉVY, Pierre. As tecnologias da inteligência. O futuro do pensamento na era da Informática.8. ed.. São Paulo: Editora 34, 1999.

LIPOVETSKY, Gilles. A sociedade da deceção. Lisboa: Edições 70, 2012.

MAROY, Christian. Towards post-bureaucratic modes of governance. IN: STEINERKHAMSI, Gita; WALDON, Florian (Eds.), World yearbook of education 2012. Policy borrowing and lending in education. London: Routledge, p. 62-93, 2012. 
MENDES, Geovana Lunardi; PACHECO, José Augusto; SOSSAI, Fernando Cesar. Currículo e "novas tecnologias" em tempos de globalização. IN: Atas do XV Encontro Nacional de Didática e Prática de Ensino - Convergências e tensões no campo da formação e do trabalho docente: políticas e práticas educacionais. Belo Horizonte: Universidade Federal de Minas Gerais, 2010.

PACHECO, José Augusto. Currículo: teoria e práxis.3. ed.. Porto: Porto Editora, 2006.

PACHECO, José Augusto. Curriculum Studies: What is the Field Today? Journal of The American Association for the Advancement of Curriculum Studies, v. 8, n. 1, p. 1-25, 2012.

PACHECO, José Augusto. Discursos e lugares das competências em contextos de educação e formação. Porto: Porto Editora, 2011.

PACHECO, José Augusto. Educação, formação e conhecimento. Porto: Porto Editora, 2013.

PAPERT, Seymour. A máquina das crianças: repensando a escola na era da informática. Porto Alegre: Artmed, 2008.

PAPERT, Seymour. Logo: computadores e educação. São Paulo: Editora S. A., 1985.

PINAR, William. O que é a teoria do currículo? Porto: Porto Editora, 2007.

POSTMAN, Neil. Tecnopólio: a rendição da cultura à tecnologia. São Paulo: Nobel, 1994.

SILVA, Bento; DUARTE, Eliane; SOUZA, Karine. Tecnologias digitais de informação e comunicação: artefactos que potencializam o empreendedorismo da geração digital. IN: MORGADO, José Carlos; SANTOS, Lucíola Licínio de Castro Paixão; PARAÍSO, Marlucy Alves (Org.), Estudos curriculares. Um debate contemporâneo. Curitiba: Editora CRV, p. 165-180, 2013.

STEINER-KHAMSI, Gita. Understanding policy borrowing and lending. Building comparative policy studies. IN STEINER-KHAMSI, Gita; WALDON, Florian (Eds.), World yearbook of education 2012. Policy borrowing and lending in education. London: Routledge, p. 5-17, 2012.

TAUBMAN, Peter. Teaching by numbers. Deconstructing the discourse of standards and accountability in education. London: Routledge, 2009.

ŽlŽEk, Slavoj. Menos que nada. Hegel e a sombra do materialismo. São Paulo: Boitempo, 2013. 
Recebido em: 21/10/2013 Aprovado em: 25/11/2013

Universidade do Estado de Santa Catarina - UDESC Programa de Pós-Graduação em Educação - PPGE

Revista Linhas

Volume 14 - Número 27 - Ano 2013 revistalinhas@gmail.com 